\title{
Bystander intervention in computer-mediated communication
}

\author{
P.M. Markey \\ Department of Psychology, University of California, Riverside, CA 92521, USA
}

\begin{abstract}
'Chat groups' were observed to demonstrate that the theoretical framework proposed in Latane and Darley's theory of bystander intervention (Latane \& Darley, 1970; The unresponsive bystander: why doesn't he help? New York, NY: Appleton-Centruy Crofts) can also be utilized to explain and predict intervention in computer-mediated communication. Specific hypotheses focused on the relations between the amount of time it took a bystander to give assistance with the gender of the individual seeking help, the number of bystanders present, and whether help was asked for by specifying a bystander's name. Results showed that gender had no significant effect on response time. Additionally, as the number of people present in a computer-mediated chat group increased, it took longer for an individual to receive help. Finally, the bystander effect was virtually eliminated and help was received much more quickly when help was asked for by specifying a bystander's name. (C) 2000 Elsevier Science Ltd. All rights reserved.
\end{abstract}

Keywords: Bystander intervention; Computer-mediated communication; Chat groups

\section{Introduction}

Human interaction via computer-mediated communication (e.g. chat rooms, news groups) does not occur in isolation. It is, therefore, probable that the same laws that have been traditionally applied to personal interaction also exist in cyberspace. For this reason, some researchers have encouraged social psychologists to draw ideas from their theories to generate hypotheses about computer-mediated communication (Kiesler, Siegal \& McGuire, 1984). This study attempts to demonstrate that the frequently studied social psychological phenomenon of the bystander effect occurs in computer-mediated communication.

In 1998, Larry Froistad, a 29-year-old computer programmer, confessed to 200 members on an Internet self-help group to deliberately setting his house on fire in order to murder his 5-year-old daughter. Although the father confessed twice to the 
murder, stating, "Amanda I murdered because her mother stood between us" and later, "...when she was asleep, I got wickedly drunk, set the house on fire, went to bed, listened to her scream twice, climbed out the window and set about putting on a show of shock and surprise", only three of the 200 news group members reported the confession to the authorities (DeCarlo, 1998; Man to plead guilty..., 1998).

Following the murder confession, some individuals hypothesized that the lack of intervention was due to misplaced sympathy or 'moral confusion' (Parger, 1998). Similar comments were echoed more than 20 years ago when Kitty Genovese was stabbed to death while 38 of her neighbors watched without coming to her aid or calling the police. However, an analysis of the case of Amanda suggests that, similar to the Kitty Genovese case, "factors other than apathy and indifference were involved" (Latane \& Darley, 1968a, p. 377).

It was previously asserted that members of the news group failed to report the murder confession of Amanda because the admission was made in a self-help group (DeCarlo, 1998; Parger, 1998). However, the responses of the members after reading the confession seem strikingly similar to those of the witnesses of the Kitty Genovese murder. The 38 witnesses in Kitty Genovese's murder did not just coldly ignore her pleas for help, rather they were "caught, fascinated, distressed, unwilling to help but unwilling to turn away, their behavior was neither helpful nor heroic; but it was not indifferent or apathetic either" (Latane \& Darley, 1970, p. 4). Likewise, the individuals who read the murder confession of Amanda did not coldly ignore it, rather they posted dozens of responses, and sent many e-mails to each other begging, "HELP ME HERE!" and asking "What can we do?" (DeCarlo, 1998, p. 40). It appears that some of their reactions contained a desire not to keep confidentiality, but to become involved. Yet even with this apparent desire to do something, only three people out of 200 actually took action.

Latane and Darley (1970) formulated a theory to help explain the shocking circumstances surrounding the murder of Kitty Genovese. Within this framework three processes must occur before a bystander gives aid to a victim; a negative resolution to any of these processes will result in the bystander not giving aid. The first process, audience inhibition, explains that the presence of other people can inhibit helping because the bystander is fearful that if they help their behavior will be negatively evaluated by other bystanders. The next process, referred to as social influence, suggests that the presence of others inhibits helping when a bystander sees that no one else is helping. Finally, diffusion of responsibility is a means of reducing the psychological cost associated with non-intervention. As a whole these processes have been labeled "the bystander effect" because they explain why, as group size increases, a bystander is less likely to aid a victim (Latane \& Nida, 1981). This paper proposes that in the case of Amanda, the bystander effect played a critical role in the lack of intervention.

While the bystander effect has been demonstrated in many diverse situations (e.g. Cramer, McMaster, Bartell \& Dragna, 1988; Pantin \& Carver, 1982; Tice \& Baumeister, 1985), to the author's knowledge there has been no investigation of this phenomenon in computer-mediated communications (e.g. chat rooms, news groups). This study evaluates the relationship between group size and the likelihood 
of receiving help in computer-mediated communications. It is proposed that, as the number of people in a group increases, it will take longer for one to receive help. Furthermore, previous research has demonstrated that, when a bystander feels obligated to help, assistance is offered more quickly and the bystander effect is greatly weakened (Latane \& Darley, 1968b; Valentine, 1980). Therefore, it is additionally hypothesized that in computer-mediated communication helping behavior increases and the bystander effect decreases when help is asked for by using the bystander's name.

\section{Method}

\subsection{Participants and materials}

Approximately 4833 participants were observed in 400 different chat groups. While there are no readily available demographic data on these specific participants, Smith and Leigh (1997) suggest that Internet users tend to be male (74\%), under the age of $30(65 \%)$, college educated $(83 \%)$, and single $(58 \%)$.

Chat groups in Yahoo! Chat (located on the World Wide Web at http://chat. yahoo.com) served as the site for data collection. Chat groups are new forms of textbased communication that allow individuals to interact with each other on the Internet in real time. Yahoo! Chat is an Internet-based free service that allows individuals from all over the world to talk to each other in chat groups. At any given time, Yahoo! Chat has 'tens of thousands' of people online interacting in hundreds of different chat groups (Yahoo!, 1998).

\subsection{Design and procedure}

Over a 30-day period, 400 different chat groups were randomly selected (excluding 'adult only' chat groups). A $2 \times 2$ factorial design was utilized to examine the effects of the gender of the individual seeking help and if help was asked for by specifying a participant's name on the amount of time it took a participant to give assistance. Additionally, a third independent variable of group size was utilized to examine the relationship between the number of people present in a chat room when help was asked for and the participant's response time. The perceived gender of the individual seeking help was manipulated by utilizing either a male (JakeHarmen) or female (SuzyHarmen) screen name. To examine what occurs when a participant feels obligated to provide assistance, help was sought by either asking all the participants in the chat group, "Can anyone tell me how to look at someone's profile?" or by randomly selecting one participant and asking the chat group participants, "(name of selected participant), can you tell me how to look at someone's profile?" A 'profile' contains a short biographical description for each user in a chat group and is easily accessed through several different methods on Yahoo!

In each of the treatment conditions, the observer first recorded the number of people present in the chat room, which ranged from two to 19, and then asked the 
stimulus question. The stimulus question was then repeated every $60 \mathrm{~s}$ until a response was given. A response was defined as any acknowledgment of the question by any participant. The dependent variable of participant response time was then recorded and the observer then left the chat room.

\section{Results}

To determine if using a participant's name increased helping behavior a $2 \times 2$ (gender of screen name $\times$ stimulus question) analysis of variance (ANOVA) was performed. This analysis revealed that assistance was received more quickly when help was asked for by specifying a participant's name $(M=36.38 \mathrm{~s})$ than when no name was specified $(M=51.53 \mathrm{~s}), F(1,396)=18.86, p<0.01$. No significant main effects or interactions involving the screen name gender were found, and the subsequent analyses were collapsed over the gender factor.

To examine whether the bystander effect occurs in chat groups, a Pearson product-moment correlation was calculated across all conditions between the number of people present in a chat group and the response time. This analysis revealed a weak relationship $(r(400)=0.14, p<0.01)$ between the number of people present in a chat group and how long it took to receive help. However, a multiple regression analysis revealed a significant interaction between group size and whether help was requested by using a specific participant's name, $F(1,396)=7.63, p<0.01$. Examination of this interaction revealed the within-group correlation was $r(200)=0.25$, $p<0.01$ when help was requested without specifying a participant's name and dropped to $r(200)=0.03, p>0.05$ when help was asked for by specifying a participant's name. A graphic representation of these results is presented in Fig. 1.

\section{Discussion}

This paper demonstrates that bystander interventions in Internet chat groups follow the same pattern as interactions in non-computer based environments. That is, as the number of people present in the chat groups increased, it took longer for an individual to receive help. Additionally, supporting Latane and Darley's (1970) theory that individuals are more inclined to aid a bystander when they feel personally responsible for helping, the bystander effect was virtually eliminated and help was received more quickly when specific individuals were asked for help by using their screen name.

One of the objectives of this paper was to suggest that the bystander effect played an important role in the poor response to the news group murder confession of Larry Froistad. Unfortunately, due to the ethical inability to simulate a highly emotional situation, such as a murder confession, this study employed a relatively unemotional situation. Accordingly, it is important to note that the results of this study may not generalize to the melodramatic environment of a murder confession. However, previous research has shown that the bystander effect tends to become 


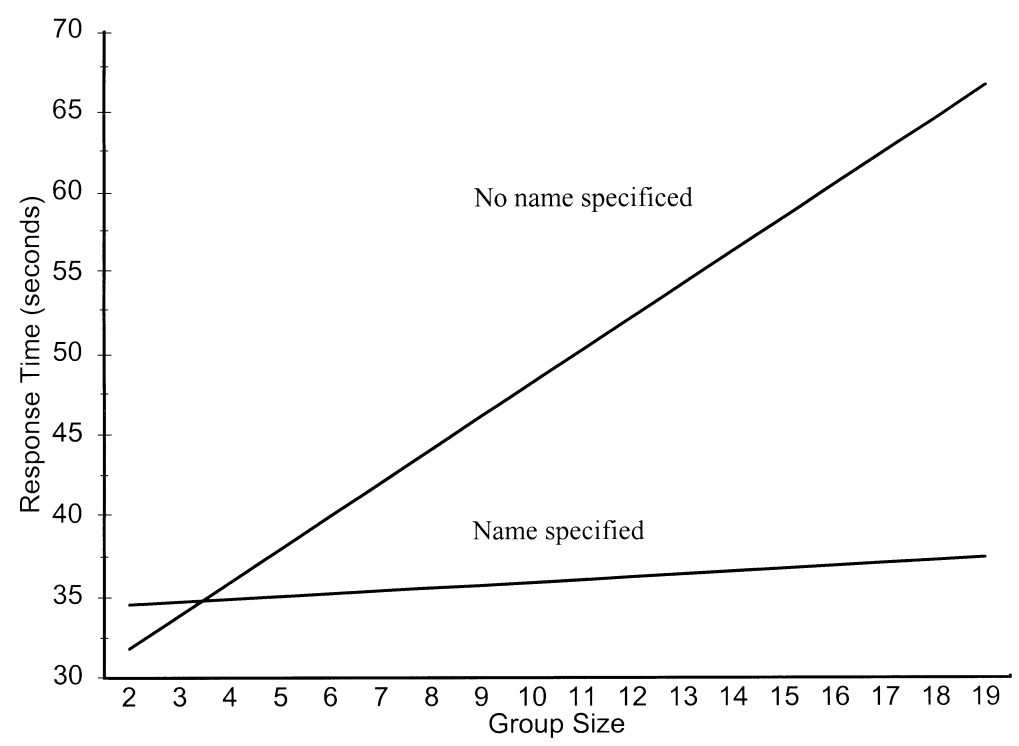

Fig. 1. Regression lines predicating response time when help was requested by specifying a bystander's name and when help was requested by not specifying a name.

more powerful as situations become more emotional or threatening (Piliavin \& Piliavin, 1972). In light of this previous finding, it can be speculated that, in computermediated communication when the situation is emotional or threatening, the bystander effect will be even more powerful than the situation presented in this study.

This paper successfully applied the social psychological theory of the bystander effect to explain and predict various behaviors inside computer-based interactions. Within the field of social psychology there exists a plethora of such theories that focus on human interaction. Since it is likely that the personal interactions that occur within computer-based environments follow many of the established theories of social psychology, researchers studying the effects of computers on human behavior are well advised to also draw upon these theories when formulating hypotheses or when interpreting results.

\section{Acknowledgments}

The author would like to thank Charlotte Castro, Shannon Wells and Daniel J. Ozer for their contributions to this report.

\section{References}

Cramer, R. E., McMaster, R. M., Bartell, P. A., \& Dragna, M. (1988). Subject competence and minimization of the bystander effect. Journal of Applied Social Psychology 18, 13, 1133-1148.

DeCarlo, E. (1998, 11 May). Murder, she read. New York Magazine, 31(18), 38-41. 
Kiesler, D., Siegal, J., \& McGuire, T. W. (1984). Social psychological aspects of computer-mediated communication. American Psychologist, 39(10), 1123-1134.

Latane, D., \& Darley, J. M. (1968a). Bystander intervention in emergencies: diffusion of responsibility. Journal of Personality and Social Psychology, 8(4), 377-383.

Latane, D., \& Darley, J. M. (1968b). Group inhibition of bystander intervention in emergencies. Journal of Personality and Social Psychology, 10(3), 215-221.

Latane, D., \& Darley, J. M. (1970). The unresponsive bystander: why doesn't he help? New York, NY: Appleton-Century Crofts.

Latane, B., \& Nida, S. (1981). Ten years of research on group size and helping. Psychological Bulletin, 89(2), 308-324.

Man to plead guilty to a killing that he first mentioned on line (1998, 5 August). The New York Times, p. A16.

Pantin, H. M., \& Carver, C. S. (1982). Induced competence and the bystander effect. Journal of Applied Social Psychology, 12(2), 100-111.

Parger, D. (1998, 7 May). Everybody has a support group these days. The Wall Street Journal, p. A22.

Piliavin, J. A., \& Piliavin, I. M. (1972). Effects of blood on reactions to a victim. Journal of Personality and Social Psychology, 23, 353-361.

Smith, M. A., \& Leigh, B. (1997). Virtual subjects: using the Internet as an alternative source of subject and research environment. Behavior Research Methods, Instruments and Computers, 29(4), 496-505.

Tice, D. M., \& Baumeister, R. F. (1985). Masculinity inhibits helping in emergencies: personality does predict the bystander effect. Journal of Personality and Social Psychology, 49(2), 420-428.

Valentine, M. (1980). The attenuating influence of gaze upon the bystander intervention effect. Journal of Social Psychology, 111(2), 197-203.

Yahoo! (1998). Yahoo! - Infordesk [Announcement posted on the World Wide Web]. Retrieved October 16, 1998 from the World Wide Web: http:/howto.yahoo.com/infodesk/yahoo_chat.html 